\title{
Efficacy of intraligamentary anesthesia in maxillary first molar extraction
}

\author{
Soukaina Tawfiq Ryalat' \\ Mohammad H Al-Shayyab' \\ Wala Amin ${ }^{2}$ \\ Saif Aldeen AIRyalat ${ }^{3}$ \\ Nosaiba Al-Ryalat ${ }^{4}$ \\ Faleh Sawair' \\ 'Department of Oral and Maxillofacial \\ Surgery, Oral Medicine, and \\ Periodontology, Faculty of Dentistry, \\ University of Jordan, Amman, Jordan; \\ ${ }^{2}$ Department of Prosthodontics, \\ Faculty of Dentistry, University of \\ Jordan, Amman, Jordan; ${ }^{3}$ Department \\ of Ophthalmology, Faculty of \\ Medicine, University of Jordan, \\ Amman, Jordan; ${ }^{4}$ Department of \\ Radiology and Nuclear Medicine, \\ University of Jordan, Amman, Jordan
}

This article was published in the following Dove Press journal:

Journal of Pain Research

\begin{abstract}
Introduction: Infiltration anesthesia (IA) is the method to anaesthetize maxillary teeth successfully. In contrast, intraligamentary anesthesia (ILA) has been used as supplementary anesthesia during tooth extraction, particularly when regional block anesthesia has failed. In this study, we compare the efficacy of and patient satisfaction with ILA vs IA when extracting maxillary first molar teeth.
\end{abstract}

Methods: Forty patients were enrolled in this study and 80 maxillary first molars extracted. All patients served as their own control, with ILA as the experimental side and IA as the control side. The two techniques were compared for efficacy using a visual analog scale (VAS) and patient satisfaction compared using a verbal rating scale (VRS).

Results: The mean VAS pain score for extraction using ILA was lower than that for IA ( $20.30 \pm 3.18$ and $13.93 \pm 1.95 \mathrm{~mm}$, respectively; $P<0.001$ ). For injection pain, the mean VAS pain score in the ILA side was higher than the IA side $(42.28 \pm 4.51$ and $31.73 \pm 3.1 \mathrm{~mm}$, respectively; $P<0.001)$. VRS results showed a higher number of patients who felt that pain during ILA was greater than expected compared with IA.

Conclusion: IA appears less painful during injection compared with ILA, and provides sufficient pain relief during extraction. However, ILA can be used when IA fails to achieve the desired pain suppression, as it provides higher extraction-pain relief.

Keywords: infiltration anesthesia, maxillary first molars, intraligamentary anesthesia, periodontal intraligamentary anesthesia

\section{Introduction}

Extraction of maxillary first molar teeth is commonly done due to different indications, including teeth affected by intractable caries and periodontitis, hypomineralization, or hypoplasia, tooth fracture, and various endodontic and periodontal problems. ${ }^{1}$ Moreover, the extraction of maxillary first molars results in significant improvement in the position of second and third molars, thus reducing the incidence of their impaction., ${ }^{2,3}$ Extraction of first molars is challenging for both the patient and the dentist, mainly due to difficulties in achieving sufficient anesthesia. ${ }^{4}$

The existence of dental nervous plexus, which is composed of specific neuronal pathways at the base of the alveolar nerves, has been described in dissections ${ }^{5,6}$ and reported in text. ${ }^{7,8}$ This plexus and possible resultant cross-innervation may explain some of the variations observed in achievement of anesthesia of the maxillary first molar. Posterior superior alveolar nerve (PSAN) block is associated with many complications, and does not always provide successful anesthesia for extraction of maxillary
Correspondence: Soukaina Tawfiq Ryalat Department of Oral and Maxillofacial Surgery, Oral Medicine, and Periodontology, Faculty of Dentistry, University of Jordan, Queen Rania Street, Amman I1 942, Jordan

Tel +962795024703

Email salryalat@yahoo.com 
first molars: it usually needs to be supplemented by buccal and palatal infiltration. ${ }^{9,10}$ Complications related to PSAN block are more common than other types, including tissue blanching, positive aspiration, and ocular complications. ${ }^{11,12}$ Infiltration anesthesia (IA) and periodontal intraligament anesthesia injection (intraligamentary anesthesia [ILA]) overcome many of these possible complications, as the mechanism and the need for subsequent injections are different. ${ }^{11}$ In IA, the needle penetrates the mucobuccal fold to deposit the solution at the level of the apices of the buccal roots of the teeth. It is the method of choice to anaesthetize maxillary first molars successfully. ${ }^{13}$ In contrast, ILA has been employed for many years as a means of achieving complete anesthesia in a tooth when regional block anesthesia has previously failed. Few adverse responses have been reported during or after injection. ${ }^{14}$ An important issue to consider is that the use of the ILA and IA are contraindicated in the presence of acute infection at the site of administration. ${ }^{15}$ In light of this controversy regarding the best anesthesia to use, we aimed to compare the efficacy of IA vs ILA for extraction of maxillary first molars.

\section{Methods}

This study was approved by the scientific committee of the Faculty of Dentistry, University of Jordan. Ethical approval was obtained (approval 1359) in accordance with research policy at Jordan University Hospital. Patients who attended the Jordan University Hospital Department of Oral and Maxillofacial Surgery were selected according to inclusion criteria of:

- bilateral maxillary first molar teeth indicated for extraction under local anesthesia

- no severe systemic disease contraindicating tooth extraction

- ability to understand given instructions fully

Exclusion criteria were:

- existence of acute infection and/or swelling at the time of surgery

- inability to tolerate the removal of the teeth concerned under local anesthesia

- inability to obtain informed consent

- severe systemic disease contraindicating tooth extraction

We obtained informed written consent from patients or their guardian (if the patient was $<18$ years of age). Before administration of the local anesthetic, each patient was instructed by the operator on the visual analog scale (VAS) being used, composed of a $100 \mathrm{~mm}$ line $(0-100 \mathrm{~mm}$, where 0 represents no pain and 100 maximum pain), and the verbal rating scale (VRS), consisting of one question: How is the pain of the extraction: less than expected, as expected, or greater than expected? During the first 5 minutes following completion of anesthetic injections, patients completed the scales to assess the amount of pain they experienced for each injection, and the mean score was taken for multiple injections.

\section{Injection techniques with randomization}

The method of anesthesia used for the left or right side was randomized by the surgeon providing it. The surgeon administered ILA to the right side for one patient and then to the left side for the following patient, and so on for IA. Regarding the sequence, the surgeon always started with the right side (regardless of the type of anesthesia). This selective randomization was blinded for the surgeon doing the extraction. The type of anesthesia was lidocaine $2 \%$ with 1:80,000 epinephrine for all injections (Xylestesin A; 3M, Saint Paul, MN, USA).

All patients received ILA on one side as the experimental side and IA on the other side as the control. Accordingly, on one side, ILA was performed through injections in the periodontal space at a slow rate of administration $(0.2 \mathrm{~mL} /$ root) over 30 seconds per root, using a conventional syringe with a 30-gauge, extra-short needle. A standard aspirating dental cartridge syringe was employed for the IA.

\section{Extraction technique}

To ensure blinding, two surgeons were involved: one for the anesthetic technique and another for the extraction. The surgeon performing the extraction was not involved in giving the injections, and did not know which side received which anesthetic technique. A consistent surgical technique with elevator and forceps was used. The side of ILA or IA was chosen randomly by the surgeon giving the anesthesia and blinded for the surgeon doing the extraction. None of the surgical procedures involved mucoperiosteal flap raising, bone removal, or suturing. Following completion of each extraction, VAS and VRS were completed by the patient.

\section{Additional anesthesia}

If an unacceptable degree of pain or discomfort were experienced during extraction, the surgical zone was reanesthetized by buccal infiltration. An additional $0.2 \mathrm{~mL} /$ tooth local anesthetic was administered to the palate when the degree of pain or discomfort was still unacceptable after an additional 5-minute delay, and the step was recorded. 


\section{Statistical analysis}

Statistical analyses were performed using SPSS 16.0 (SPSS, Chicago, IL, USA). VAS scores were normally distributed for each injection side and for each group according to the diagnosis, as determined visually by histograms and a Shapiro-Wilk test result of $>0.05$. Paired-sample $t$-tests were used to compare mean VAS values of the two sides for injection and extraction. The Wilcoxon signed-rank test was also used to compare the VRS data of the two sides and the McNemar test used to compare the difference in terms of the need for additional injections. Results were considered significant if $P<0.05$. To correct for multiple testing, we used the Bonferroni method.

\section{Results}

Forty patients ( 29 males and eleven females, mean age 32.15 [11-65] years) from Jordan University Hospital's Department of Oral and Maxillofacial Surgery were involved in this study. There were 80 maxillary first molar teeth extracted in total: eleven for orthodontic purposes, 21 periodontally involved, 12 fractured, ten with periapical lesions, and 26 that were profoundly carious. The mean VAS pain score for injection in the ILA side was $42.28 \pm 4.51 \mathrm{~mm}$, while that for the infiltration side was $31.73 \pm 3.1 \mathrm{~mm}$. The difference between the means of the two methods was statistically significant $(P<0.001$, paired-sample $t$-test; Table 1$)$. The mean VAS pain score for extraction using ILA was $20.30 \pm 3.18 \mathrm{~mm}$, while that for IA was $13.93 \pm 1.95 \mathrm{~mm}$. There was significant difference between the two sides $(P<0.001$; Table 1$)$.

Table I Comparison of VAS pain scores between the two sides from injection and extraction

\begin{tabular}{lllll}
\hline & Group & $\mathbf{n}$ & Mean & SD \\
\hline Injection & Intraligamentary & 40 & 42.28 & 4.51 \\
& Infiltration & 40 & 31.73 & 3.10 \\
& -value $^{\mathrm{a}}$ & $<0.001$ & & \\
Extraction & Intraligamentary & 40 & 20.30 & 3.18 \\
& Infiltration $^{\text {a }}$ & 40 & 13.93 & 1.95 \\
& -value $^{\mathrm{a}}$ & $<0.001$ & & \\
\hline
\end{tabular}

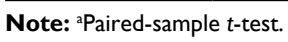

For extraction pain in the experimental side (ILA), 30 of 40 patients $(75 \%)$ indicated that it was "as expected", none indicated it was "less than expected", and ten rated it as "greater than expected". For extraction pain on the control side (IA), 26 of 40 patients (65\%) indicated that it was "as expected", nine indicated that it was "less than expected", and only five rated it as "greater than expected" $(P=0.006$; Table 2). Furthermore, six of 40 patients required additional buccal infiltration without palatal injection for extraction pain at the experimental side (ILA) compared with 15 of 40 patients on the control side (IA; buccal and palatal), the difference approaching statistical significance $(P=0.064$; Table 2$)$.

\section{Discussion}

Pain constitutes a large component in dental anxiety, where two main sources for dental pain are identified: pain from the procedure (eg, tooth extraction) and pain before the procedure (eg, injections). ${ }^{16}$ In this study, where we compared pain scores for both anesthetic injection and extraction of first molars, we found that mean VAS pain score for extraction using ILA was lower than that for IA. Considering injection pain, the mean VAS pain score in the ILA side was higher than the IA side.

Knowledge of the branching patterns of the trigeminal nerve, additional innervations, and presence of accessory canals and foramina should be carefully considered when choosing the best anesthetic plan for optimizing oral surgery procedures. ${ }^{17}$ ILA has been employed for many years, with a high success rate achieved using several techniques. ${ }^{14,18}$ A study found that both intraligamentary and intraosseous injections are effective techniques and can be used as an alternative when other techniques fail. ${ }^{19}$ In a randomized trial comparing different techniques of anesthesia for mandibular teeth in patients experiencing pulpitis, IA allowed more painfree treatment than ILA. ${ }^{20}$

In posterior maxillary tooth extraction, a common technique used is the PSAN block, with a success rate of $70 \%-100 \%{ }^{21}$ However, some patients complained of inadequate sensory blockade at the time of extraction and required augmentation with an additional buccal and/or

Table 2 Comparison of degree of VRS pain and number of additional buccal injections needed in the two sides

\begin{tabular}{llllll}
\hline & $\mathbf{n}$ & $\begin{array}{l}\text { Less than } \\
\text { expected }\end{array}$ & $\begin{array}{l}\text { As } \\
\text { expected }\end{array}$ & $\begin{array}{l}\text { Greater than } \\
\text { expected }\end{array}$ & $\begin{array}{l}\text { Requiring additional } \\
\text { infiltration }\end{array}$ \\
\hline $\begin{array}{l}\text { Intraligamentary } \\
\text { Infiltration }\end{array}$ & 40 & 0 & 30 & 6 & 10 \\
P-value & 40 & 9 & 26 & 5 & 15 \\
\hline
\end{tabular}

Notes: aWilcoxon signed-rank test; 'McNemar test.

Abbreviation: VRS, verbal rating scale. 
palatal injection. Possible complications associated with PSAN block include transitional diplopia, damage to the pterygoid venous plexus, and hematoma formation. ${ }^{9,12}$ Local ILA may prove more efficient than PSAN block, especially in those with inadequate sensory blockade. This may be due to the more accurate and direct root anaesthetization in ILA. ${ }^{8}$ However, this technique was shown here to cause a slightly higher pain response during injection compared to IA. Moreover, ILA is associated with higher blood levels of epinephrine and the anesthetic agent, which might lead to several cardiovascular changes. ${ }^{22}$ Therefore, the ILA technique should be considered as an alternative when IA fails to provide adequate sensory blockade. It is also used as a supplement by most dental practitioners, because it does not yield consistently deep-enough anesthesia during dental procedures. $^{23}$

The ILA is recommended for use in extraction of teeth with irreversible pulpitis. ${ }^{24}$ The result of the first published clinical assessment of ILA showed that success rates ranged from $60 \%$ for endodontic therapies to $100 \%$ for periodontal therapies and tooth extraction. ${ }^{14}$ Similarly, previous investigations have confirmed that pulp anesthesia with IA or the nerve-block technique is more difficult to achieve in the presence of irreversible pulpitis or unhealthy teeth compared to normal healthy ones. ${ }^{17}$

\section{Limitations}

In this study, only one anesthetist and one surgeon performed all the work, so operator experience in either type of anesthesia was ignored. Future studies should consider investigating differences in mean VAS scores for different indications for extraction. Future studies should also pay more attention to the incomplete randomizations that may be due to specific signs associated with each anesthetic technique (eg, puncture marks).

\section{Conclusion}

ILA- and IA-injection techniques may be used in dentistry to induce local anesthesia. However, although both techniques provide alternative approaches to establishing effective anesthesia for extraction of maxillary first molar teeth, IA appears less painful during injection and provides sufficient pain relief during extraction. However, ILA can be used when IA fails to achieve the desired pain suppression, as it provides higher extraction-pain relief.

\section{Disclosure}

The authors report no conflicts of interest in this work.

\section{References}

1. Sandler PJ, Atkinson R, Murray AM. For four sixes. Am J Orthod Dentofacial Orthop. 2000;117(4):418-434.

2. Tarazona B, Paredes V, Llamas JM, Cibrián R, Gandia JL. Influence of first and second premolar extraction or non-extraction treatments on mandibular third molar angulation and position: a comparative study. Med Oral Patol Oral Cir Bucal. 2010;15(5):e760-e766.

3. Livas C, Halazonetis DJ, Booij JW, Katsaros C. Extraction of maxillary first molars improves second and third molar inclinations in class II division 1 malocclusion. Am J Orthod Dentofacial Orthop. 2011;140(3):377-382.

4. Jälevik B, Möller M. Evaluation of spontaneous space closure and development of permanent dentition after extraction of hypomineralized permanent first molars. Int J Paediatr Dent. 2007;17(5):328-335.

5. Fitzgerald MJ, Scott JH. Observations on the anatomy of the superior dental nerves. Br Dent J. 1958;104:205-208.

6. McDaniel WL. Variation in nerve distributions of the maxillary teeth. J Dent Res. 1956;35(6):916-921.

7. Rusu MC. Microanatomy of the neural scaffold of the pterygopalatine fossa in humans: trigeminovascular projections and trigeminal-autonomic plexuses. Folia Morphol (Warsz). 2010;69(2):84-91.

8. Heasman PA. Clinical anatomy of the superior alveolar nerves. $B r J$ Oral Maxillofac Surg. 1984;22(6):439-447.

9. Hayden J. The innervation of the maxillary first permanent and primary molars as determined by the deposition of local anesthetic solutions: a preliminary report. Acta Odontol Scand. 1965;23(2):147-162.

10. Lustig JP, Zusman SP. Immediate complications of local anesthetic administered to 1,007 consecutive patients. J Am Dent Assoc. 1999;130(4):496-499.

11. Boynes SG, Echeverria Z, Abdulwahab M. Ocular complications associated with local anesthesia administration in dentistry. Dent Clin North Am. 2010;54(4):677-686.

12. Loetscher CA, Melton DC, Walton RE. Injection regimen for anesthesia of the maxillary first molar. J Am Dent Assoc. 1988;117(2):337-340.

13. Ogle OE, Mahjoubi G. Local anesthesia: agents, techniques, and complications. Dent Clin North Am. 2012;56(1):133-148.

14. Malamed SF. The periodontal ligament (PDL) injection: an alternative to inferior alveolar nerve block. Oral Surg Oral Med Oral Pathol. 1982;53(2):117-121.

15. Meechan JG. How to overcome failed local anesthesia. Br Dent J. 1999;186(1):15-20.

16. McNeil DW, Helfer AJ, Weaver BD, Graves RW, Kyle BN, Davis AM. Memory of pain and anxiety associated with tooth extraction. $J$ Dent Res. 2011;90(2):220-224.

17. Rodella LF, Buffoli B, Labanca M, Rezzani R. A review of the mandibular and maxillary nerve supplies and their clinical relevance. Arch Oral Biol. 2012;57(4):323-334.

18. Bavitz JB. Dental management of patients with hypertension. Dent Clin North Am. 2006;50(4):547-562.

19. Moore PA, Cuddy MA, Cooke MR, Sokolowski CJ. Periodontal ligament and intraosseous anesthetic injection techniques: alternatives to mandibular nerve blocks. JAm Dent Assoc. 2011;142 Suppl 3:S13-S18.

20. Kanaa MD, Whitworth JM, Meechan JG. A prospective randomized trial of different supplementary local anesthetic techniques after failure of inferior alveolar nerve block in patients with irreversible pulpitis in mandibular teeth. $J$ Endod. 2012;38(4):421-425.

21. Adatia AK. Regional nerve block for maxillary permanent molars. $\mathrm{Br}$ Dent J. 1976;140(3):87-92.

22. Biocanin V, Brkovic B, Milicic B, Stojic D. Efficacy and safety of intraseptal and periodontal ligament anesthesia achieved by computercontrolled articaine + epinephrine delivery: a dose-finding study. Clin Oral Investig. 2013;17(2):525-533.

23. Santopolo JL. Using the STA Single Tooth Anesthesia System unit. 2010. Available from: https://www.aegisdentalnetwork.com/id/2010/08/usingthe-sta-single-tooth-anesthesia-system-unit. Accessed July 3, 2018.

24. Parirokh M, V Abbott P. Various strategies for pain-free root canal treatment. Iran Endod J. 2014;9(1):1-14. 
The Journal of Pain Research is an international, peer reviewed, open access, online journal that welcomes laboratory and clinical findings in the fields of pain research and the prevention and management of pain. Original research, reviews, symposium reports, hypothesis formation and commentaries are all considered for publication
The manuscript management system is completely online and includes a very quick and fair peer-review system, which is all easy to use. Visit http://www.dovepress.com/testimonials.php to read real quotes from published authors.

Submit your manuscript here: https://www.dovepress.com/journal-of-pain-research-journal 